\title{
Learning and Motivation in Thailand: A Comparative Regional Study on Basic Education Ninth Graders
}

\author{
Jyrki Loima $^{1,2} \&$ Jutarat Vibulphol ${ }^{3}$ \\ ${ }^{1}$ Faculty of Education, Chulalongkorn University, Thailand \\ ${ }^{2}$ Faculty of Social Sciences and Business Studies, University of Eastern Finland, Finland \\ ${ }^{3}$ Faculty of Education, Chulalongkorn University, Thailand \\ Correspondence: Jyrki Loima, University of Eastern Finland, P. O. Box 101, 80101 Joensuu, Finland. Tel: \\ 358-449-775-629. E-mail: jyrki.loima@gmail.com
}

Received: May 13, 2015 Accepted: July 29, 2015 Online Published: December 28, 2015

doi:10.5539/ies.v9n1p31 URL: http://dx.doi.org/10.5539/ies.v9n1p31

\begin{abstract}
This qualitative research studied regional motivation and learning of the basic education 9th graders in Thailand. Second topic was the school size and its possible effect on motivation. Furthermore, the data gave an opportunity to discuss, whether international research on motivation and learning was valid in Thai classrooms. The informants were randomly selected from northern, north eastern, central, and southern regions of the country. Altogether 12 schools, ranging from smaller than 500 students to larger with more than 1500 students, participated. Three teachers and their students from each school assessed their learning and motivation into a questionnaire after lessons. Researchers selected randomly two male and female students to represent each class. Research questions were:

What is the motivation and learning of the students in the four main regions of the Thailand?

Does the school size affect the motivation and learning? If it does, what is the impact?

Research findings revealed that the most motivated Thai students study in south. The internal motivation wasn't low anywhere, however, but it could easily drop to a situation-based interest or even less. Second, the motivation was higher in classes, in which teachers analyzed students' motivation and learning in the same way as students did. Third, the more the students liked the teacher, the better their motivation was. Regarding school size effects, the trend favored smaller units. To foster the future development, this study urges to study motivation in all teachers training. Second, teachers' personal motivation needs surveys in a broad context.
\end{abstract}

Keywords: motivation, learning, teacher, student, school size

\section{Introduction: Objectives, Data and Importance of the Study}

The objectives of this qualitative research were, first, to analyze comparatively regional learning and motivation of the basic education 9th graders in Thailand. As such, this paper was a continuation and extension of the qualitative study Loima and Vibulphol (2014) made on 9th graders learning and motivation in private, public and university demonstration schools of Bangkok. Second, this study aimed to find out whether school size affected students' motivation to learn. In terms of academic theories, data used in this study also offered an opportunity to discuss whether the outcomes of international research on motivation and learning would be consistent with this regional comparison or analysis of school size. The participating students and schools for this qualitative study were randomly selected from four main regions of Thailand: Northern (N), North Eastern (NE), Central (C), and Southern (S). Three public schools of different sizes, ranging from small (fewer than 500 students), medium (from 500-1500 students) to large units (more than 1500 students), from each region were selected on the basis of their willingness to represent the region. This paper addressed two research questions (RQs):

- What is the motivation and learning of the students in the four main regions of the Thailand?

- Does the school size affect the motivation and learning? If it does, what is the impact?

This research was the first comparative, qualitative regional analysis on the motivation and learning of 9th graders in Thailand. Second, it was the first study that collected and analyzed data from learning and motivation in different sizes of institutions and compared them with previous research outcomes. The intention was to 
identify new features, but as a qualitative study this did not aim to have the final word on theories. It rather promoted the understanding of these complex phenomena that have been related to motivation and learning. In addition, it was to give guidelines for adjusting the motivation, or engagement, in classrooms. In a wider context, public statements on education policies as well as basic education curricula and teacher education curricula development and revisions may also benefit from this study. Finally, it was timely to investigate something other than performance in school subjects in Thai basic education, since 21st century learning environments change faster than any curricula or content may do and require life-long learning skills and "internal" motivation (Alderman, 2008; Darling-Hammond, 2006; Deci \& Ryan, 2002; Dörnyei, 2001; Hämäläinen \& Välijärvi, 2008; Salmela-Aro, 2009). To add one more important point, another research outcome aimed to be practical: to engage so-called network schools and universities in the active development of and dialogue about enhancing their motivating activities on the basis of these outcomes (see Palmer, 2009; Loima \& Vibulphol, 2014).

In terms of research ethics, the school names were kept confidential from the very beginning as well as any personal information of the participants or informants. Only researchers had access to the research data that was deleted, once the study was ready. The limitations of the study could have been created by an "internal" process of instruction that the schools might have had before the researchers arrive. On the other hand, in a few cases teachers were not prepared to have any outsiders in their lessons and the questionnaire was only shared with the teachers and students after the lessons. This indicated that there had not been any systematic or specific preparations which the researchers were unaware of. Another limitation was the difficulty to assess and discuss internal motivation with a situational data collection. This was taken into consideration when data collection was planned, formatted and structured.

The data were collected in January-February 2015 from three lessons in each school, comprising three different core subjects: English, mathematics, and science. These classes were selected by the school administrators to be answer questions and to be observed by a pair of researchers. The teacher and the students from each classes participated in the study on voluntary basis. After the lessons, they were asked to provide their opinions about the students' learning and motivation and about the methods that the teacher used to motivate the students during the lesson. The teacher assessed the students' learning and motivation and the students commented on how much they learned, how interesting the lesson or topic was and how their attitudes and activities were during the lesson. The questionnaires (Appendices 1-2) were designed based on previous motivation research theories and patterns but the number of questions was purposefully kept low and indicators clear (Reeve, 2009; Loima \& Vibulphol, 2014; also Jang, Reeve, \& Deci, 2010). They were also planned to be easily converted into figures on the motivation of the students as the answers were given as simple arithmetic values that indicated negative (0), to low (1), moderate (2) or high motivation (3).The teacher and the students were also given an information sheet, which described the objectives of the study and the confidentiality of their personal information and the questionnaire. Finally, two male and two female students' questionnaires from each class were randomly selected to represent their group.

In relation to the selection of subjects, all three subjects are required in the national core curriculum in Thailand (Ministry of Education, 2008) and are a part of the core subjects in the Partnership for $21^{\text {st }}$ Century Skills Framework for $21^{\text {st }}$ Century Learning (Partnership for $21^{\text {st }}$ Century Skills, n.d.). In addition, mathematics and science are two of the literacies being tested in PISA: Program for International Student Assessment (Organization for Economic Co-operation and Development (OECD), n.d.), while English is an essential competency for international communication around the world (Fiedler, 2011; Johnson, 2009; Kirkpatrick, 2008).

The data were discussed in light of selected previous studies on motivation, its importance and crucial meaning for any learning in addition to the school atmosphere, teaching practices, and their effects on students' motivation (e.g., Alderman, 2008; Moskovsky et al., 2012; Palmer 2009). According to previous research, this study also separates intrinsic (here "internal") motivation as a long-lasting one from the short-termed extrinsic (here "external") motivation when this is needed (Ryan, 1995; Niemiec \& Ryan, 2009; also Ryan \& Deci, 2009). Various studies have shown positive relationships between motivation and learning achievement (Choosri \& Intharaksa, 2011; Dweck, 2002; Hagger et al., 2015; Jang, Kim, \& Reeve, 2012; Loima \& Vibulphol, 2014; Yunus, Suraya, \& Wan-Ali, 2009) and variables related to learning such as autonomy (Ling, 2013) and engagement (Assor, Kaplan, \& Roth, 2002; Assor, Kaplan, Kanat-Maymon, \& Roth 2005; Jang, Kim, \& Reeve, 2012; De Witte \& Rogge, 2013; Jang, Reeve, \& Deci, 2010; Skinner, Chi, \& the Learning-Gardens Educational Assessment Group, 2012). Furthermore, the data analysis applied reflections on motivation from the self-determination theory (SDT) presented by Niemiec and Ryan (2009). They stated that people naturally like to learn. They are interested in the surroundings and have tendencies to engage themselves in learning. 
Consequently, education should be the process that enhances natural human characteristics and keeps people 'motivated' to learn. However, studies have shown the opposite-student's internal (long-lasting) motivation dropped from upper elementary school to high school (Gottfried, Fleming, \& Gottfried, 2001). To explore this phenomenon, previous research has also contributed on content subjects. The findings all suggest that teacher behaviors and instructional approaches play an important role in enhancing students' motivation for learning (Alderman, 2008; Dörnyei, 2001; Dweck, 2002; Jang, Kim, \& Reeve, 2012; Moskovsky et al., 2012; Palmer, 2009; Reeve, 2009; Tsai et al., 2008; Urhahne, 2015; Wiśniewska, 2013; also Assor et al., 2002, 2005; Hagger et al., 2015). Teachers' controlling, institutional approaches were found to suppress students' curiosity, engagement and enthusiasm for learning while teaching that promoted autonomy fostered long-term internal motivation and engagement in even challenging tasks (Assor et al., 2002; Dweck, 2002; Garn \& Jolly, 2013; Jang, Reeve, \& Deci, 2010; Loima \& Vibulphol, 2014; Moskovsky et al., 2012; Urhahne, 2015). Moskovsky et al. (2012) concluded that teachers simply have the crucial role in enhancing learners' motivational "levels". Jang, Reeve, and Deci (2010) pointed out that the teachers' role ranges from highly controlling to highly autonomous and affected students' engagement accordingly. Niemiec and Ryan (2009) commented that teachers' external control, close supervision, monitoring and evaluation, along with rewards and punishment, cause the students' interests in learning to be replaced by boredom and anxiety, or they may even feel 'alienated' in class. In the worst case, students may be in the state of 'amotivation'-losing their personal interest to learn what is taught and only relying on teacher's external control to make the learning occur (Dweck, 2002; Niemiec \& Ryan, 2009). In Thailand, Loima and Vibulphol (2014) found that the students' internal motivation seemed to be enhanced better when the teachers gave attention and space for individual learning. The more controlling the teacher was, the lower the motivation of the 9th grade students also was, due to a focus on the necessary performance to "get the lesson done". Irrespective of all the previous studies, there is no research that could present a sound or explicit framework for a regional comparison on motivation and learning. Some tools were offered by Alderman (2008), who discussed successful school characteristics, such as common and shared vision of the development of all the members of that (particular) learning community, including children and adolescents. Regarding the elder students, Chung-Do et al (2013) found in their 4-year follow-up study that smaller high school class sizes could create a stronger connection with the teacher and enhance the motivation of the students. In addition to these contributions, a new comparison will challenge, or add, the theories and approaches so far.

\section{Regional Motivation of 9th Graders}

In relation to regional motivation-and RQ 1 of this study-of the Thai 9th graders, a summary of the findings is presented in figure 1. Using the arithmetic values for the data, the summary also makes it possible to separate the schools regionally. To focus on the participants, teachers' remarks and students' answers ("I was strongly interested/ topic was OK /not interesting topic but learning is important", Appendix 2) were summarized into a regional framework. The observers' supporting comments were completely left out of these ratings. Internal and external motivation indicators were included into a single rating. In those various cases in which the motivation was "split" into, for example, between low and moderate or moderate and high, the indicating value was presented as decimals. This explains the minor differences inside the main scale. 


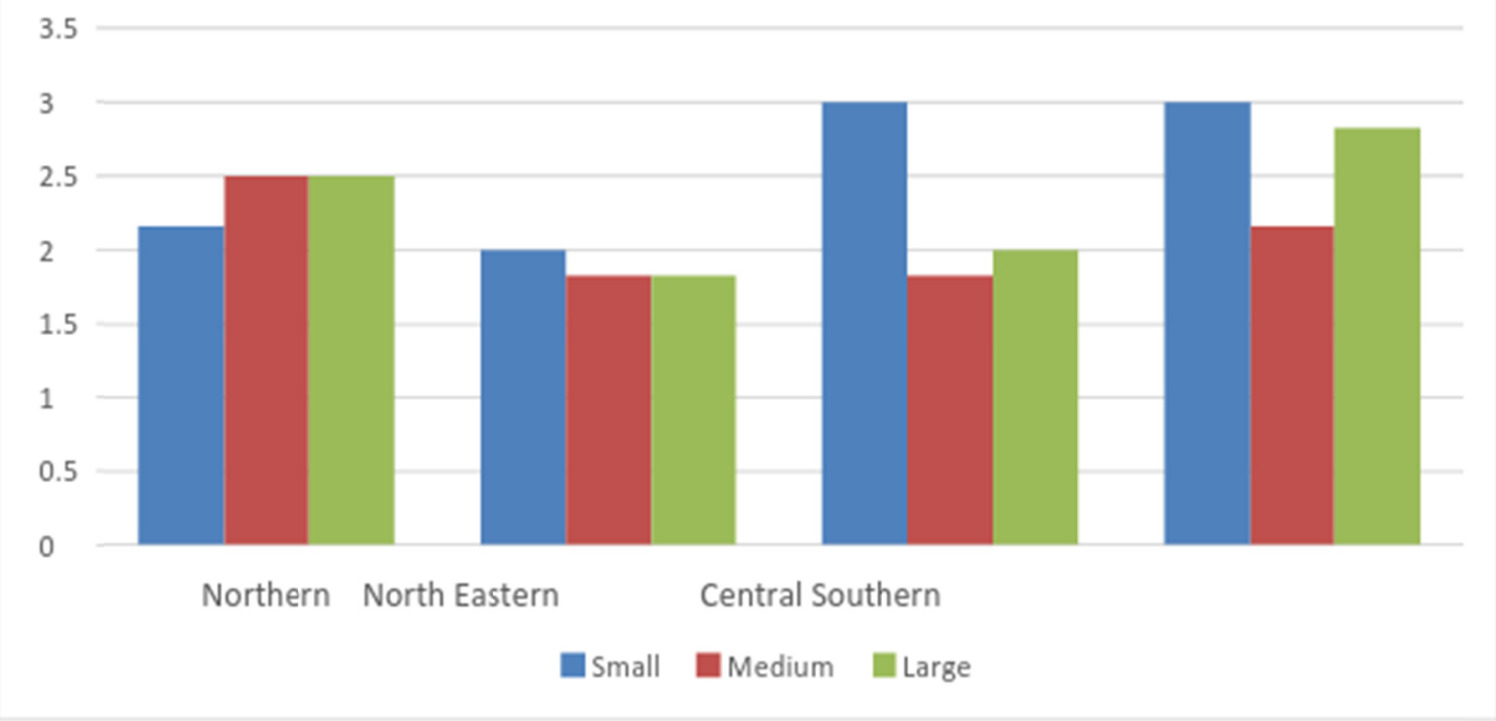

Figure 1. Motivation and learning of 9th graders in four main regions of Thailand

It is evident is that regional differences existed-and exist. As a main finding and trend it seemed to be obvious that all the 9th graders have at least between low to moderate motivation to learn-and, accordingly, were motivated to study in their basic education schools at an age in which students in other countries tend to show lower levels of motivation (cf. Alderman, 2008; Reeve, 2009; Wiśniewska, 2013). According to the main data findings, most of the students also learned. The majority of lessons were teacher-centered-as was shown by the questionnaire comments on motivation strategies and methods made by the teachers. The fact that students reported learning, indicated that the teachers were significantly "liked". This kind of "liking" of the teacher or subject also was the mentioned reason for learning in so many students' responses in the data (cf. Alderman, 2008; Assor et al., 2002; Loima \& Vibulphol, 2014; Moskovsky et al., 2012). As an enhancing motivation factor, the "liking" of the teachers that was repeated in students' questionnaires regardless of the gender of the teacher or the student, made a "not interesting" lesson or subject worth trying to learn "some", as several students replied (De Witte \& Rogge, 2013; Dweck, 2002; Loima \& Vibulphol, 2014; cf. Assor et al., 2002; Niemiec \& Ryan, 2009). Consequently, the teachers' crucial role that was found in the data can be seen as a sound source of students' external and, accordingly, situation-based motivation (Chung-Do et al., 2013; Loima \& Vibulphol, 2014; Moskovsky et al., 2012; Niemiec \& Ryan, 2009; Reeve, 2009; Palmer, 2009; also Salmela-Aro, 2009). In this framework it was highly interesting to find out that the outcomes Assor et al. (2002) presented on the basis of their data (in Israel) had no correlation with Thai students' motivation or teachers' behavioral models or motivating strategies and practices found in this research data. While teachers' behaviors which enhanced or suppressed autonomy predicted the students' engagement in Israel, in this data it was more about "liking" that could compensate for the "not-interesting topic" or any teachers' behavioral motivation method in Thai schools and yielded up to moderate or even high levels of motivation (Assor et al., 2002; cf. Loima \& Vibulphol, 2014; also Alderman, 2008). This also made some applications of the SDT theory less valid in the evaluation of students' motivation, since according to Assor et al. (2002) in SDT people may develop their learning autonomy, once they realize their personal goals and values (cf. Jang et al., 2010; Niemiec \& Ryan, 2009). This was not the trend in the regional findings of this study. As a source of external motivation, it was enough for Thai students to "like" the teacher to get them learn "some" or "most" of the topics and express their external motivation. In terms of continuous internal motivation, this finding may also be characterized as a series of repeated external motivation "bursts" (lessons) of a particular, liked teacher. However, the data did not show how the motivation of the same students was on those lessons in which teachers were not liked. On the other hand, SDT stated that frustration lead to poorer learning outcomes (Niemiec \& Ryan, 2009) and that trend was found in the regional data as well.

As also was shown in Figure 1, the students' motivation was moderate to high in Northern and Southern regions. What were the common characteristics of the most motivated students in Southern and Northern regions? In those areas the teachers were and/or the learning was "liked" in almost all schools and the students' external motivation and learning tended to arise from this "liking" (cf. Niemiec \& Ryan, 2009; see Assort, 2002; Dweck, 
2002). Some learners seemed to replace their missing internal motivation-when indicating that the "lesson was not interesting"-with "liking the teacher" and wanted to behave accordingly. These kind of external elements have again a close relationship with Salmela-Aro's (2012) socio-cultural factors, like institutional structures and encouraging feedback, that was reflected in teachers' motivating methods to create a positive learning atmosphere in the classroom (see also Skinner et al., 2012). Almost all the teachers aimed consciously for this motivation pattern with evident success (see, Jang et al., 2010; Moskovsky et al., 2012; Niemiec \& Ryan, 2009; Salmela-Aro, 2009; also Assor et al., 2002). On the other hand, one may assume that the students could have adjusted their goals and may not have learnt the way they stated in less interesting lessons, if the teachers' role had not been so crucially important and learning or teachers had not been liked in these schools (Chung-Do et al., 2013; Dweck, 2002; Moskovsky et al., 2012; Niemiec \& Ryan, 2009; Salmela-Aro, 2009). Regarding the external motivation in the data, teachers' role, position and motivating measures seemed to enhance overall motivation to learn in regional contexts even more than previous research elsewhere has shown (cf. Assor et al., 2002; Jang et al., 2010; Niemiec \& Ryan, 2009). Following Alderman's (2008) terminology, self-regulated levels of learning - to reach "optimum motivation" - were not so much needed for moderate to good motivation among Thai students as was their need or importance elsewhere (Alderman, 2008). In terms of applied SDT theories, teachers' common strategies to create a positive learning atmosphere also made students to feel welcome at school and supported accordingly their "relatedness" in terms of membership (Alderman, 2008; De Witte \& Rogge, 2013; Skinner et al., 2012).

On the other hand, the North Eastern region seemed to have more students who did not concentrate on the topic, were "not interested" and did "other things" during the lessons. Motivation was lower. Consequently, in these "negative" dimensions, SDT was in line with the data and motivation disengagement of some Thai students. This lack of interest or motivation may have led to passive, distracting and negative emotions, or "amotivation" as was seen in findings especially in the North Eastern region (Niemiec \& Ryan, 2009; also Dweck, 2002; cf. Chung-Do et al., 2013; Jang et al., 2010). Irrespective of this regional match with SDT, another SDT-based trend for positive engagement (Jang et al., 2010) was not so much a behavioral way to better external motivation or learning outcomes among Thai 9th graders, but rather was in most cases replaced with "liking" the teacher or learning, which were also the findings from the North East. In brief, teachers' motivational strategies, methods or choices meant less in terms of external motivation but were adequate as such to get the students engaged in "some" or "most of" learning (cf. Alderman, 2008; Assor et al., 2002; Chung-Do et al., 2013; Wolff et al., 2015). Regarding internal motivation, data from the North East spoke for "liking" the learning that replaced the lacking interest in the topic, or subject, up to a moderate status of internal motivation of Thai 9th graders. Since the teacher remained the same throughout the school year, "liking" him or her was a more permanent state of mind. Even though the topic of lesson was not interesting, the "liking" of learning kept students engaged enough to learn "some". Teachers in those cases were likely to be able to understand "success and failure" and see the value of their students, encouraging them in a suitable way thereby creating a positive learning atmosphere (cf. Alderman, 2008).

Consequently, the below moderate ratings in the medium-sized schools were found in the North East and Central regions. What did the data reveal? To exemplify, one school in the North East was analyzed in detail. In this particular school, some students showed signs of internal motivation as Niemiec and Ryan (2009) described but several students expressed that they did not find the lessons or subjects interesting and a few students expressed "liking" the teachers. Instead of active participation, some of them "did something else". This refers to the motivational disengagement as described by Jang et al. (2010) (cf. Assor et al., 2002). Furthermore, in a classroom situation this kind of tendency may suffocate the external motivation of those students who willingly readjust their goals in line with the variable social, or students' socio-cultural, context (Salmela-Aro, 2009). In a class with a big number of students the socio-cultural context and motivation may rapidly change and differ. Subsequently, students' motivation may be affected more by the immediate feedback that the classmates give in the lesson situation than by the teacher, who may concentrate only on the first row students, allowing them more space for choices, critiques and relevant actions (Assor et al., 2002; Dweck, 2002; Jang et al., 2010; Niemiec \& Ryan, 2009; Salmela-Aro, 2009). In this study, in which also new theory-based approaches are sought, this kind of data trend, in which the students reported "doing something else" in the lesson, may be called "acculturated external interest" that is based on an immediate "reward"-meaning temporary attention received, for example, from peers. For instance, any middle and/or back row student may readjust their goals and actions to receive "rewarding" attention from other students when performing something other than the lesson topic (Salmela-Aro, 2009). The data from the students provided a good amount of supporting answers for this kind of "acculturated external interest", while the teachers were also able to see that in some classes. This kind of socio-cultural readjustment may aim for gaining "membership" or a sense of belonging to a group (Alderman, 2008). In 
addition, if the students did not like the teacher, the situation-based and short-termed motivation did not rise higher than low to moderate, even though teachers' motivational strategies were the same as in more successful cases. This finding may also indicate the lack of welcoming feelings and missing sense of "relatedness" or meaningful performances in those situations in which teachers were not liked (cf. Chung-Do et al., 2013; Niemiec \& Ryan, 2009; Skinner et al., 2012).

To conclude the first RQ, motivation to learn had regional tendencies and was "liking"-based. In terms of internal motivation, the overwhelming students' reflection in the data was that they liked learning or the subject. Even though the topic was not interesting, they expressed in line with the teachers' comments that most of them learned "most" or "some" of the topic. This again refers to STD, natural interest and "liking" in learning as well as meaningful "relatedness" (Assor et al., 2002; Chung-Do et al., 2013; Dweck, 2002; Jang et al., 2010; Niemiec \& Ryan, 2009; Salmela-Aro, 2009; Skinner et al., 2012). These findings were not so evident in the first qualitative study on motivation and learning of Thai 9th graders in Bangkok (Loima \& Vibulphol, 2014). A new trend in this regional data was the previously named "acculturated external motivation" in which the teacher's crucial socio-cultural role and meaning could be replaced temporarily by classmates when immediate feedback, or "reward" was needed to support the low to moderate external motivation. Students' changing and adapting cultural identity and psycho-cognitive needs to belong (to the class community) tend to accept positive feedback, or "reward" for being recognized as a member, given by classmates when the teachers did not pay attention enough in these occasions (cf. Alderman, 2008; Niemiec \& Ryan, 2009; Skinner et al., 2012).

\section{School Size and the Motivation}

In this research the schools were divided into "small" (fewer than 500 students), "medium" (500-1,500 students) and "large" (more than 1,500 students). They were all studied together to see whether the school size affects students' motivation (e.g., Alderman, 2008; Chung-Do et al., 2013; also Skinner et al., 2012). As stated in RQ2, the researchers were also interested in "how" the school size could affect motivation to understand the context. Irrespective of possible expectations, a "small" school did not indicate smaller class sizes for participating students. This variable was unpredictable. A small class size could be found in a large school as well. Using the same scale from low (1) to high (3) motivation, Figure 2 presents again "split" cases in which motivation was seen, for example, between moderate and high. The motivation rating included both external and internal indicators. Observers' remarks were not included to give all the space for local viewpoints of teachers and students (see Appendices 1-2).

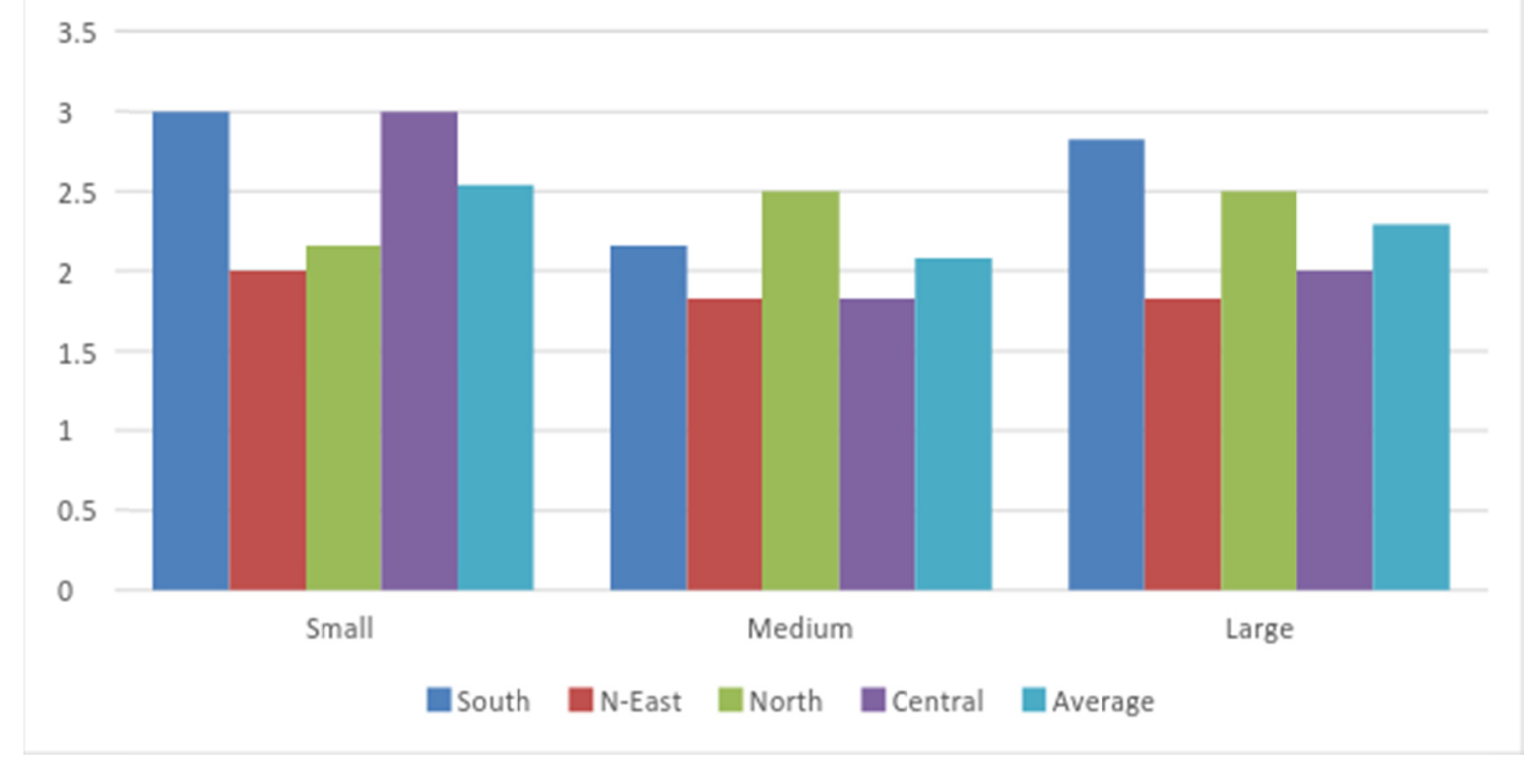

Figure 2. Motivation to learn in small, medium and large schools

To start with the averages, the main finding was that motivation to learn was highest in small-sized schools. The second main trend was rather surprising: large sized schools seemed to have "higher" motivation than medium 
sized schools (cf. Alderman, 2008; Skinner et al., 2012). A simple, tentative conclusion may be that school size did not directly speak for higher motivation levels once the school had more than 500 students, even though a small-sized school seemed to have some positive effects on motivation enhancement. Consequently, a single factor for the "lost" motivation in bigger schools may have been simply the missing "relatedness" and "competence" when a student got easily lost in the crowd and corridors while a mass of other students rushed to take the front row seats to assure their "belonging" and "membership" (Alderman, 2008; Chung-Do et al., 2013; Niemiec \& Ryan, 2009; Salmela-Aro, 2009; Skinner et al., 2012). An unintentional finding that all the North Eastern schools had low to moderate motivation regardless of their size was beyond the focus of the research questions and, subsequently, left for further analysis.

The highest levels of motivation were found in small sized schools, in particular Southern and Central regions. In both cases the teachers and students gave similar signals and assessment of the students' high motivation to learn, as SDT indicated when students' fundamental needs were accomplished (Niemiec \& Ryan, 2009; Skinner et al., 2012; also Alderman, 2008; Chung-Do et al., 2013). It seemed to be a clear trend that once the teacher was "liked", the learning was also liked and the students had strong (internal) interest in the topics. Only one of the students "did not like" the subject in these small-sized schools. Consequently, a positive learning atmosphere was successfully created by the teachers to further enhance the internal motivation. The other motivating method they widely used was "encouraging students at the group level". As such it had a connection to the learning context, socio-cultural factors like the characteristics of these institutions and, consequently, to the behavior of students, as Salmela-Aro (2009) contributed (also Chung-Do et al., 2013; Skinner et al., 2012). An interesting finding in these highly motivated classes was that the teachers' motivating strategies were not differentiated between experienced "expert" or starting "novice" (Wolff et al., 2015). Regardless of the age or experience, the teachers used the same motivation strategies and paid less attention to maintaining discipline, or so-called 'classroom management', in these highly motivated schools (cf. Alderman, 2008; Wolff, 2015; Skinner et al., 2012). Another success factor may be identified from socio-cognitive signs of a successful school contributed by Alderman (2008). Their concern goes beyond the curricula and focuses on the holistic development and motivation of the members, including learners of all ages-students and all adolescents (Alderman, 2008; also Salmela-Aro, 2009). If the socio-culturally important "cultural identity" of a learner at the institutional level offers this kind of mutual membership and sense of "belonging", the crucial signs and elements of sustainable internal motivation exist and are further supported by the beliefs of students and teachers (Chung-Do et al., 2013; Skinner et al., 2012). In such a school environment teachers may challenge students by establishing learning environments and conditions that allow optimal work, safety and promote personal responsibility of all students. This was the case in small-sized schools and students in all regions in this study. Socio-cognitively and psychologically important "membership" (Chung-Do et al., 2013; Salmela-Aro, 2009; Skinner et al., 2012) of a learning community was obviously somehow lost in most of the medium and large schools and replaced to some extent by other disengaging behavioral models, like giving up and doing "other things". Another reason for this kind of cognitive absence and uninterested presence could be students' "self-handicapping" behavior, as Alderman (2008) called it. According to him, students avoid anticipated failure by disabling themselves from learning activities and use "self-helplessness" or "self-handicapping" as excuses. Teachers' beliefs may support this kind of avoidance behavior, if their imagined or experienced and even indirectly expressed students" "ability" was seen to be more valuable than efforts they had pursued in learning occasions (Alderman, 2008; also Salmela-Aro, 2009).

According to the data, teachers in medium and large sized schools in the North East and Central regions estimated the students" motivation higher than the students with one exception. Regardless of the "liking" that students there also had, teachers' motivating strategies, such as "displaying patience" or encouraging on the "group level", were not appealing enough to the students. Several students learned "most" or "some", showing thus engagement for lower performance. Maybe the different understanding of existing motivation even affected the students indirectly. On the other hand, this kind of connection of differently expressed "beliefs" from each other indicated that students did not expect to get "effort-based" appreciation or support from their teachers and, accordingly, their basic motivational needs were not properly met (see Alderman, 2008; Niemiec \& Ryan, 2009, Skinner et al., 2012). Consequently, their learning was at lower levels but teachers in those schools were not fully able to see that. One of them said that students did not learn even though all the students assessed that they learned "some" of the topics. On the other hand, other teachers in medium to large sized schools also in most cases tended to overestimate the learning processes compared with students' views according to the data. No suitable or supporting strategies were then implemented sufficiently well to enhance the motivation of those few students who had a strong interest to the topic. Signs of internal motivation existed, but were not supported in a way that would have promoted "membership" of a learning community or, for example, the relatedness of the students (Alderman, 2008; Skinner et al., 2012). Following the theories, when no meaningful tasks or teachers' attention were available, "self-made 
helplessness" may easily occur (Alderman, 2008; Skinner et al., 2012; also Niemiec \& Ryan, 2009). Consequently, it may change a learner's cultural identity. Another, adapted cultural identity, missing relatedness and learned helplessness may lead to seeking new "memberships" of informal classmate groups that have other interests and rewards (Alderman, 2008; Salmela-Aro, 2009).

Irrespective of this trend in medium and large sized schools, a Southern large school had the highest motivation indicators among these two school sized groups. What can account for this? Teachers there were able to assess the learning outcomes and motivation of the students consistently with the students' own reports. All of the students learned "most" or "all". They explicitly had a strong interest and they also "liked" learning. A single student expressed no interest in the lesson, while another said the same but regarded the teacher to be good and studied for that (external) motivating reason. In light of socio-cognitive theories it again was about the students' relatedness, "belonging" and membership; the teachers' supporting attitudes and space-giving methods; and expectations that were based on the membership idea of that school as a learning community of all age groups (Alderman, 2008; Chung-Do et al., 2013; Loima \& Vibulphol, 2014; Niemiec \& Ryan, 2009; Skinner et al., 2012; also Wolff, 2012). The large school in the South was able to arrange meaningful learning for students and to create a positive environment and support the competence, or self-worth of students (Alderman, 2008; Niemiec \& Ryan, 2009; Skinner et al., 2012).

To close the analysis of school size, another exception from the trends mentioned previously should be noted. From all medium sized schools, the Northern one showed higher levels of motivation than the others. What were the reasons for such a higher level? The overwhelming majority of the students expressed that they liked learning and had a strong interest in the topic. One of them commented on feelings of being "not fully" concentrated, while two students found the topic "not interesting" but regarded learning to be important. The same student said they had learned "some", while other students said they had learned "all" or "most". Teachers' strategies were to pay special attention to the weakest students, motivate at the group level and aim for a positive learning atmosphere. One teacher also commented on using "external" motivating sources, like test scores. According to data, teachers were able to recognize the students' learning and motivation more precisely than in other medium sized schools. As was the case in some previous higher motivation levels, these findings also indicated the socio-cultural and cognitive motivation support that promoted students' feelings of membership and belonging, competence in performance and meaningful studies and rewarding working atmosphere in this school (Alderman, 2008; Niemiec \& Ryan, 2009; Salmela-Aro, 2009; Skinner et al., 2012), in addition to "liking" the subjects and teachers as peculiar characteristics. In the context of this data and study, those elements made the middle sized Northern school able to have higher motivation than the other schools of the same size.

As a conclusive answer to RQ2, the school size made a difference in motivation favoring smaller schools. The optimal climate in classrooms as well as the characteristics of a successful school (Alderman, 2008; also Chung-Do et al., 2013) were probably more easily agreeable in small schools, even up to a level of a well-functioning successful team of children and co-learning adolescents. However, there also were some bigger schools - and teachers - that could create an enhancing atmosphere for moderate to high motivation. Finally, the statement "big is beautiful" did not fit into higher motivation and learning levels of students or positively challenging and engaging motivating contexts in this study.

\section{Conclusions and Suggestions}

Teachers play a crucial role in Thai students' learning motivation. Most motivated 9th graders went to schools in, first, Southern and, second, Northern regions. The mentioned areas had teachers, who could create a positive learning atmosphere in the classrooms to enhance motivation and learning successfully. In addition, these teachers were able to interpret their students' learning and motivation in the same way as the students. If the teachers and the students saw the motivation and learning in a different light, it indicated a lower motivation. Apart from the studies on motivation elsewhere, exceptional characteristics in Thai classrooms were the firm connections that "liking" the teachers had with enhanced external motivation. Furthermore, internal motivation indicators were quite much focused around the other "likings": subject and learning. Teachers' behaviors towards suppressing or supporting autonomy, self-regulated learners' needs or other "fundamental" indicators that expressed higher motivation elsewhere, did not match directly as crucial motivating factors in Thai classrooms. It was more about being "related" in the sense of belonging, being liked, and liking. A challenging new finding was a kind of "acculturated external interest" that occurred, if the students found neither lessons nor topics to be interesting, or even did other things during the lessons. They readjusted their learning goals accordingly.

The results of this study with the combination of situation-based, socio-cultural and socio-cognitive acculturated interests of students and "liking" would deserve further research to create sound strategies for enhancing Thai 
teacher education and teachers' in-service training. Currently too much positive motivation seems to be wasted or ignored. Another main research finding was that motivation to learn was higher in the schools of small size. Regarding motivation in the 21st century to be a key factor for all learning, the cultural contexts of the schools should be further researched as well as the "identities" and activities they offer to all students. What makes a certain school a successful one apart from the school size? What kind of theory for a successful learning society could be implemented in schools? Third, while "liking" deserves its culture-bound research, the development of teacher-centered classroom activities would be worth another study. Fourth, since it seems to be the case that individual students need "belonging" more than autonomy-supporting activities even in the 9th grade, it would be considerably proactive and useful to study, where would the students like to belong after compulsory education? Last but not least, if some teachers seemed to be better motivators, how about the teachers' own motivation: is it an external remnant from the past or a modern vision?

\section{References}

Alderman, K. M. (2008). Motivation for Achievement (3rd ed.). New York: Routledge.

Assor, A., Kaplan, H., \& Roth, G. (2002). Choice is good, but relevant is excellent: Autonomy-enhancing and suppressing teacher behaviors predicting students' engagement in school work. British Journal of Educational Psychology, 72, 262-278.

Assor, A., Kaplan, H., Kanat-Maymon, Y., \& Roth, G. (2005). Directly controlling teacher behaviors as predictors of poor motivation and engagement in girls and boys: The role of and anxiety. Learning and Instruction, 15, 397-413. http://dx.doi.org/10.1016/j.learninginstruc.2005.07.008

Choosri, C., \& Intharaksa, U. (2011). Relationship between motivation and students' English learning achievement: A study of the second-year vocational certificate level Hatyai Technical College Students. The $3^{\text {rd }}$ International Conference on Humanities and Social Sciences Proceedings. Retrieved from http://tar.thailis.or.th/bitstream/123456789/665/1/006.pdf

Chung-Do, J., Filibeck, K., Goebert, D. A., Arakawa, G., Fraser, D., Laboy, J., \& Minakami, D. (2013). Understanding students' perceptions of a high school course designed to enhance school connectedness. Journal of School Health, 83(7), 478-484. http://dx.doi.org/10.1111/josh.12055

Darling-Hammond, L. (2010). New policies for $21^{\text {st }}$ century demands. (Interviewed by J. Bellanca). In J. Bellanca, \& R. Brandt (Eds.), $21^{\text {st }}$ Century Skills: Rethinking How Students Learn (pp. 33-50). Bloomington, IN: Solution Tree Press.

De Witte, K., \& Rogge, N. (2013). Dropout from secondary education: All's well that begins well. European Journal of Education, 47(4), 131-149. http://dx.doi.org/10.1111/ejed.12001

Deci, E. L., \& Ryan, R. M. (2002). The Paradox of Achievement: The Harder You Push, The Worse It Gets. In A. Joshua (Ed.), Improving Academic Achievement: Impact of Psychological Factors on Education (pp. 62-84). New York, NY: Academic Press. http://dx.doi.org/10.1016/B978-012064455-1/50007-5

Deci, E. L., \& Ryan, R. M. (2008). Self-determination theory: A macrotheory of human motivation, development, and health. Canadian Psychology, 49(3), 182-185. http://dx.doi.org/10.1037/a0012801

Dörnyei, Z. (2001). Teaching and Researching Motivation. Essex, England: Pearson Education Limited.

Dweck, C. S. (2002). Messages that Motivate: How Praise Molds Students' Beliefs, Motivation, and Performance (in Surprising Ways). In A. Joshua (Ed.), Improving Academic Achievement: Impact of Psychological Factors on Education (pp. 38-58). New York, NY: Academic Press. http://dx.doi.org/10.1016/B978-012064455-1/50006-3

Fiedler, S. (2011). English as a lingua franca - a native- culture-free code? Language of communication vs. language of identification. Apples-Journal of Applied Language Studies, 5(3), 79-97. Retrieved from http://apples.jyu.fi/issue/view/7

Garn, A., \& Jolly, J. L. (2014). High ability students' voices on learning motivation. Journal of Advanced Academics, 25(1), 7-24. http://dx.doi.org/10.1177/1932202X13513262

Gottfried, A. E., Feming, J. S., \& Gottfried, A. W. (2001). Continuity of academic intrinsic motivation from childhood through late adolescence: A longitudinal study. Journal of Educational Psychology, 93(1), 3-13. http://dx.doi.org/10.1037//0022-0663.93.1.3

Hagger, M. S., Sultan, S., Hardcastle, S. J., \& Chatzisarantis, N. L. D. (2015). Perceived autonomy support and autonomous motivation toward mathematics activities in educational and out-of-school context is related to 
mathematics homework behavior and attainment. Contemporary Educational Psychology, 41, 111-123. http://dx.doi.org/10.1016/j.cedpsych.2014.12.002

Hämäläinen, K., \& Välijärvi, J. (2008). Challenges for Education. In J. Loima (Ed.), Facing the Future: Developing Teacher Education (pp.13-47). Helsinki, Finland: Gaudemus, Helsinki University Press.

Jang, H., Reeve, J., \& Deci, E. L. (2010). Engaging students in learning activities: It is not autonomy support or structure but autonomy support and structure. American Psychological Association, 102(3), 588-600. http://dx.doi.org/10.1037/a0019682

Johnson, A. (2009). The Rise of English: The language of globalization in China and the European Union. Macalester International, 22, 131-168. Retrieved from http://digitalcommons.macalester.edu/macintl/vol22/iss1/12

Kirkpatrick, A. (2008). English as the official working language of the Association of Southeast Asian Nations (ASEAN): Features and strategies. English Today, 24, 27-34. http://dx.doi.org/10.1017/S0266078408000175

Loima, J., \& Vibulphol, J. (2014). Internal interest of external performing? A Qualitative study on motivation and learning of $9^{\text {th }}$ graders in Thailand basic education. Journal of Education and Learning, 3(3), 194-203. http://dx.doi.org/10.5539/jel.v3n3p194

Ministry of Education, Thailand. (2008). Basic Education Core Curriculum B.E. 2551 (A.D. 2008). Retrieved from http://www.academic.obec.go.th/web/doc/d/147

Moskovsky, C., Alrabai, F., Paolini, S., \& Ratcheva, S. (2013). The effects of teachers' motivational strategies on learners' motivation. Language Learning, 63(1), 34-62. http://dx.doi.org/10.111/j.1467-9922.2012.00717.x

Niemiec, C. P., \& Ryan, R. M. (2009). Autonomy, competence, and relatedness in the classroom: Applying self-determination theory to educational practice. Theory and Research in Education, 7(2), 133-144. http://dx.doi.org/10.1177/1477878509104318

Palmer, D. H. (2009). Student interest generated during an inquiry skills lesson. Journal of Research and Science Teaching, 46 (2), 147-165. Retrieved from http://dx.doi.org/10.1002/tea.20263

Partnership for 21 st Century Skills (n.d.). Framework for $21^{\text {st }}$ Century Learning. Retrieved from http://www.p21.org/our-work/p21-framework

Reeve, J. (2009). Why teachers adopt a controlling motivating style toward students and how they can become more autonomy supportive. Educational Psychologist, 44(3), 159-175. http://dx.doi.org/10.1080/00461520903028990

Ryan, R. M. (1995). Psychological needs and the facilitation of integrative processes. Journal of Personality, 63, 397-427. Retrieved from http://entrevistamotivacional.pt/wp-content/uploads/2014/01/1995-RyanPsychological-needs-and-the-facilitation-of-integrative-processes.pdf

Salmela-Aro, K. (2009). Personal goals and well-being during critical life transitions: The four C's-challenging, choice, co-agency and compensation. Advances in Life Course Research, 14, 63-73. http://dx.doi.org/10.1016/j.alcr.2009.03.003

Skinner, E. A., Chi, U., \& The Learning-Gardens Educational Assessment Group. (2012). Intrinsic motivation and engagement as "active ingredients" in garden-based education: Examining models and measures derived from self-determination theory. The Journal of Environmental Education, 43(1), 16-36. http://dx.doi.org/10.1080/00958964.2011.596856

The Organisation for Economic Co-operation and Development (OECD). (n.d.). About PISA. Retrieved from http://www.oecd.org/pisa/aboutpisa/

Tsai et al. (2008). What makes lessons interesting? The role of situational and individual factors in three school $\begin{array}{lllll}\text { subjects. Journal of Educational } & \text { Psychology, }\end{array}$ http://dx.doi.org/10.1037/0022-0663.100.2.460

Urhahne, D. (2015). Teacher behavior as a mediator of the relationship between teacher judgment and students' motivation and emotion. Teaching and Teacher Education, 45, 73-82. http://dx.doi.org/10.1016/j.tate.2014.09.006

Wiśniewska, D. (2013). Interest and interest-enhancing strategies of adolescent EFL learners. ELT Journal, 67(2), 210-219. http://dx.doi.org/10.1093/elt/ccs079 
Yunus, S. A. M., \& Ali, W. Z. W. (2009). Motivation in the learning of mathematics. European Journal of Social Sciences, $\quad 7(4), \quad 93-101 . \quad$ Retrieved from http://starcomptechnology.com/wp-content/uploads/2013/03/motivation-in-learning-math.pdf

\section{Appendix A}

\section{Questionnaire for the Teacher}

Instruction: This questionnaire consists of three parts. Please respond to each item sincerely to express your own opinions/ideas about your lesson/class. There is no right or wrong answer for each item. Please answer ALL questions.

Please give some information about yourself.

Mr. $\square$ Ms.

School

Thank you for your cooperation! Your name and personal information will be kept confidential and will not be used for any purposes other than arranging the data collection.

\section{Part I: Motivation and Learning}

1. Do you think your students achieved the goals that you had for this lesson? Choose one level.

( ) a. all students achieved the goals at all levels

( ) b. most of the students did it at a good level

( ) c. most of the students did it at the satisfactory level

( ) d. most of the students did not reach the learning objectives during the lesson

Please add your comments

2. What kind of motivating methods did you use during the lesson?

( ) a. Demanding students to behave in a certain way

( ) b. Paying special attention and giving support to the weakest students

( ) c. Supporting individual student's motivation development and capacity for autonomous learning

() d. Encouraging students at the group level for learning as a class

( ) e. Correcting the wrong/unexpected answers immediately

( ) f. Allowing time for students' self-paced learning and answering

( ) g. Motivating students using external sources, e.g., scores, punishment

() h. Relying on internal sources of motivation, e.g., interests, positive learning atmosphere

3. What is your estimation of the motivation level of the students during the lesson?

( ) a. high

( ) b. moderate

( ) c. low 
() d. negative

\section{Appendix B}

\section{Questionnaire for the students}

Instruction: This questionnaire consists of four questions which ask you to reflect on your OWN experiences from the lesson. Please respond to each item sincerely to express your own opinions/ideas about the lesson. There is no right or wrong answer for each item. Please answer ALL questions.

1. How would you describe your learning in this level? Choose one level.

( ) a. I learned all the topics of the lesson.

( ) b. I learned most topics of the lesson.

( ) c. I learned some topics of the lesson.

( ) d. I did not learn most topics of the lesson.

2. Select one of the followings to describe your learning during the lesson.

( ) a. I was strongly interested in the topic and had a good motivation.

( ) b. The topic was OK.

( ) c. The topic was not so interesting but I felt it important to learn

( ) d. I was not interested in this topic.

( ) e. Instead of learning, I did something else during the lesson

( ) f. I learned something else rather than the topic/content during the lesson.

What? (please specify)

3. Describe your ways of and interest on learning.

( ) a. I like to learn and I pay close attention to the lesson.

( ) b. I do not like learning.

( ) c. I do not fully concentrate on learning. I think about other things during the lessons

( ) d. I do not like learning but this teacher is good and I like his/her teaching.

( ) e. I do not like learning but I like this subject.

4. I would like to improve the following things in the lesson, so I can learn better.

\section{Please give some information about yourself.}

Gender Male Female

Class M.3/........... School

GPAX

Thank you for your cooperation! Your name and personal information will be kept confidential and will only be used for the purpose of this study. 


\section{Copyrights}

Copyright for this article is retained by the author(s), with first publication rights granted to the journal.

This is an open-access article distributed under the terms and conditions of the Creative Commons Attribution license (http://creativecommons.org/licenses/by/3.0/). 